
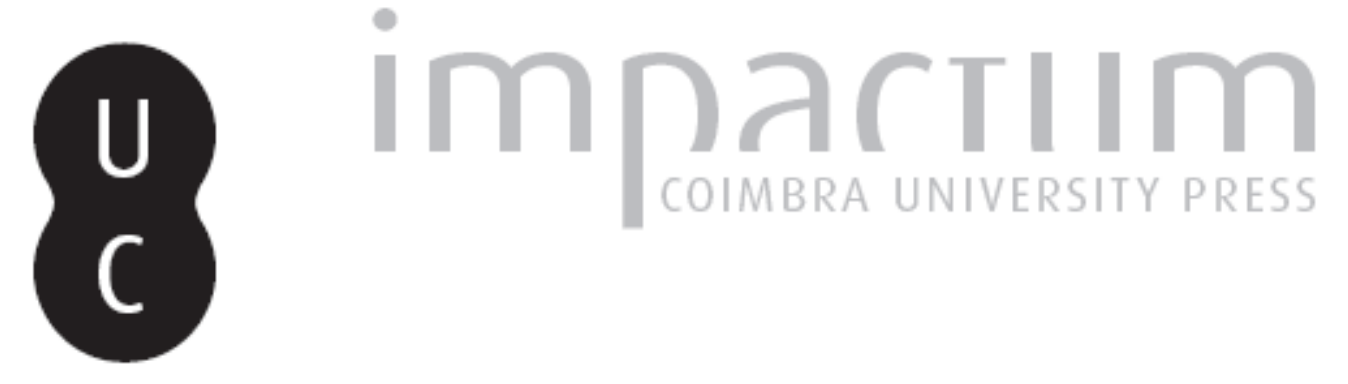

\title{
[Recensão a] ENCHEIRIDION DE EPICTETO
}
Autor(es):
Moreira, Valter Duarte
Publicado por: Annablume Clássica; Imprensa da Universidade de Coimbra
URL persistente:
URI:http://hdl.handle.net/10316.2/37019
DOI:
DOI:http://dx.doi.org/10.14195/1984-249X_15_18
Accessed : $\quad$ 26-Apr-2023 15:12:27

A navegação consulta e descarregamento dos títulos inseridos nas Bibliotecas Digitais UC Digitalis, UC Pombalina e UC Impactum, pressupõem a aceitação plena e sem reservas dos Termos e Condições de Uso destas Bibliotecas Digitais, disponíveis em https://digitalis.uc.pt/pt-pt/termos.

Conforme exposto nos referidos Termos e Condições de Uso, o descarregamento de títulos de acesso restrito requer uma licença válida de autorização devendo o utilizador aceder ao(s) documento(s) a partir de um endereço de IP da instituição detentora da supramencionada licença.

Ao utilizador é apenas permitido o descarregamento para uso pessoal, pelo que o emprego do(s) título(s) descarregado(s) para outro fim, designadamente comercial, carece de autorização do respetivo autor ou editor da obra.

Na medida em que todas as obras da UC Digitalis se encontram protegidas pelo Código do Direito de Autor e Direitos Conexos e demais legislação aplicável, toda a cópia, parcial ou total, deste documento, nos casos em que é legalmente admitida, deverá conter ou fazer-se acompanhar por este aviso.

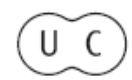




\section{5}

jul/dez

2015

issn 2179-4960

e-issn 1984-249-X
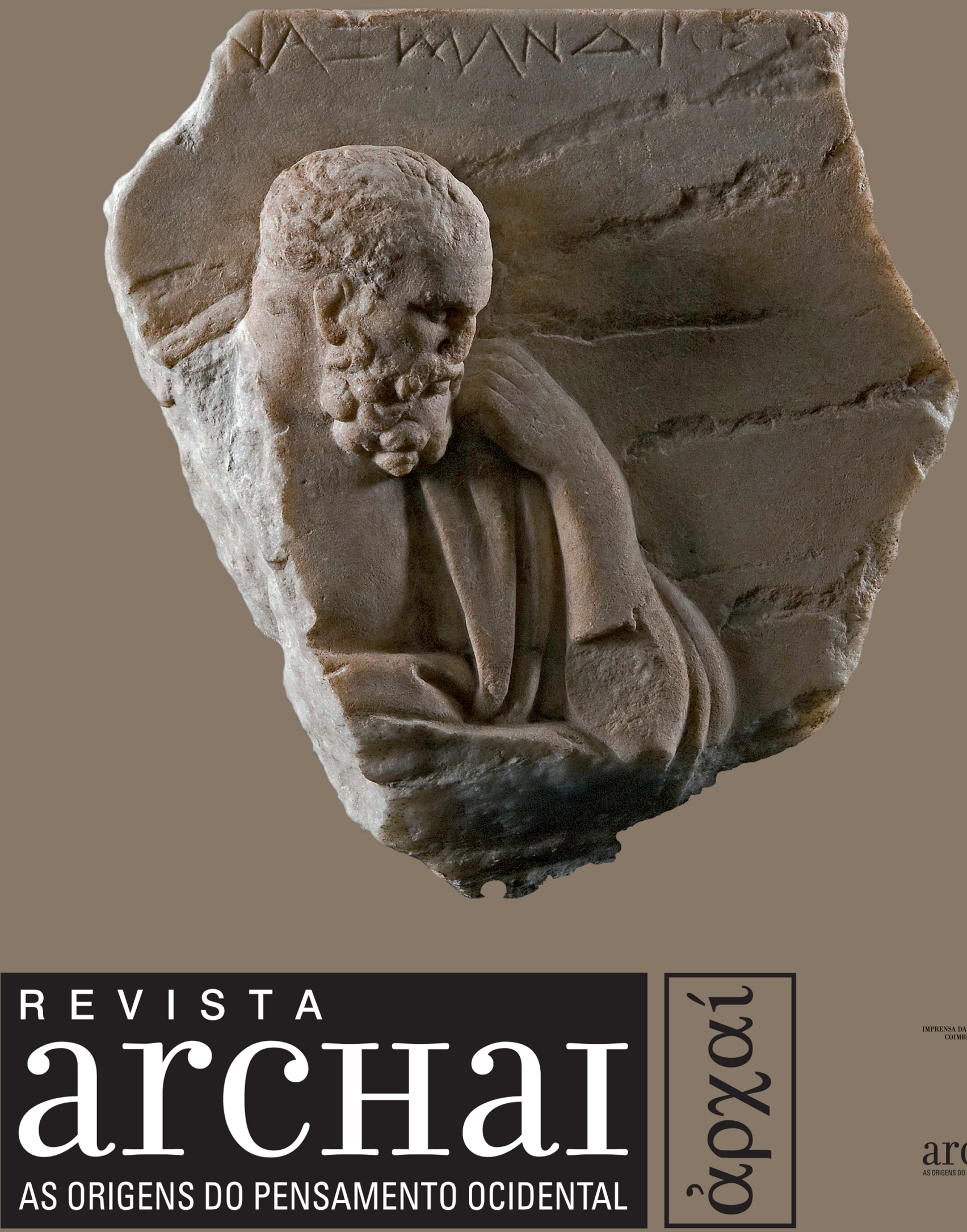

ARCHAI JOURNAL: ON THE ORIGINS OF WESTERN THOUGHT

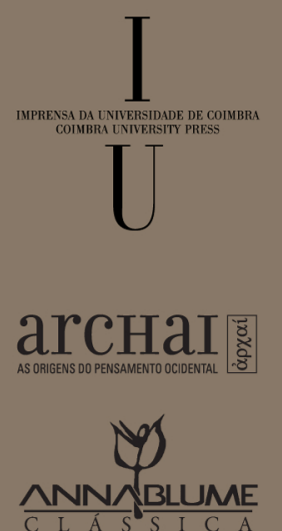




\section{ENCHEIRIDION DE EPICTETO}

MOREIRA, V. D. (2015). Resenha. EPICTETO DE HIERÁPOLIS (2014). Encheirídion de Epicteto. Introdução, Tradução e Comentários de Aldo Dinucci e Alfredo Julien. Coimbra, Imprensa da Universidade de Coimbra. Archai, n. 15, jul. - dez., p. 169-170

DOI: http://dx.doi.org/10.14195/1984-249X_15_18
* Universidade Federal de Sergipe - Sergipe, Brasil valtermoreira2@gmail.com

\section{Valter Duarte Moreira}

Em Abril deste ano foi publicada pela Universidade de Coimbra a tradução comentada e anotada do Encheirídion de Epicteto, tradução que é fruto de um trabalho minucioso resultante da união de esforços de dois especialistas em história e filosofia clássicas, o doutor em história social Alfredo Julien (USP) e o doutor em filosofia Aldo Dinucci (PUC-RJ). Epicteto, Frígio, de Hierápolis, liberto de Epafrodito (um dos guarda-costas do imperador Nero), influente filósofo estoico no século I d.C., ministrava aulas em Nicópolis. Segundo fontes clássicas, Epicteto nada teria escrito, mas seu pensamento nos chegou por um de seus alunos, Flávio Arriano Xenofonte, que compilou suas aulas e as transformou em oito livros, as Diatribes, das quais nos chegaram apenas as quatro primeiras e, delas, uma síntese do pensamento estoico, o Encheirídion, a partir da qual, aqueles já familiarizados com os princípios teóricos dessa escola poderiam usar como uma ferramenta sempre à mão quando fosse necessário aplicar seus ensinamentos. Embora não tendo sido escritas por Epicteto, a tradição atribui tais obras à sua autoria.

A obra em questão há alguns anos recebe a atenção concentrada desses dois pesquisadores. Efetivamente, em 2007, Aldo Dinucci publicou Manual de Epicteto: aforismos da sabedoria estoica (São Cristóvão, EdiUFS), uma edição de divulgação 
contendo uma tradução preliminar com introdução e notas. Esta obra teve nova edição em 2008. Neste mesmo ano, Aldo Dinucci e Alfredo Julien uniram-se para traduzir os fragmentos epicteteanos (Epicteto: testemunhos e fragmentos. Aldo Dinucci; Alfredo Julien (Org.). São Cristóvão: EdiUFS, 2008 ${ }^{1}$. Após receber financiamento do $\mathrm{CNPq}$, a mesma equipe trabalhou na edição bilíngue da obra, com publicação em 2012 (Encheirídion de Epicteto, edição bilíngue. São Cristóvão, EdiuFS: $2012^{2}$ ). Notícia dessa publicação foi veiculada pela revista eletrônica de filosofia Crítica na Rede ${ }^{3}$. No mesmo ano, juntamente com essa obra, tivemos a publicação da terceira edição da versão de divulgação, contendo a nova tradução, agora intitulada: Introdução ao Manual de Epicteto (São Cristóvão: EdiUFS, $2012^{4}$ ). Uma versão compacta desta tradução foi também publicada pela revista de filosofia clássica Archai ${ }^{5}$. Desses esforços somados, resultou a publicação de que ora nos ocupamos, que contém uma tradução burilada ao extremo, além de estar repleta de notas de esclarecimento acerca dos termos técnicos utilizados pelo estoicismo, bem como de eventos históricos e personagens (históricos ou míticos) citados na obra e de temas relevantes para o entendimento da obra.

Essa tradução é constituída de uma introdução, na qual consta uma Nota biográfica sobre Epicteto, Epafrodito e Musônio, indicando as referentes fontes de informação. Em segundo lugar, encontra-se uma seção intitulada $A$ quem se destina e para que serve $o$ Encheirídion de Epicteto, onde são esclarecidas algumas questões fundamentais sobre as práticas do estoicismo.

Na seção seguinte estão informações sobre a Recepção e transmissão do Encheirídion de Epicteto: da era bizantina aos nossos dias, capítulo igualmente rico em detalhes quanto às fontes, no qual constam evidências textuais da importância e relevância que a obra alcançou no decorrer do tempo, seguido de uma breve seção intitulada Sobre a divisão em capítulos do Encheirídion de Epicteto, expondo os critérios tomados pelos principais pesquisadores e tradutores desta obra em todo o mundo, quando seguem ou não a tradição e por qual razão.

Na seção seguinte, há informações substanciais acerca de como o estabelecimento do texto grego desta obra foi fundamental para balizar posteriores estudos epicteteanos. Em tal capítulo, apontam-se quais autores foram responsáveis por esse trabalho e qual o ano de publicação de suas obras. Um dos principais foi Boter que, para estabelecer o texto grego do Encheirídion, baseou-se (i) nos códices que contêm 0 texto do Encheirídion, (ii) nos códices que contêm o Comentário de Simplício, (iii) nos títulos contidos em alguns códices do Comentário de Simplício, (iv) nos títulos suplementares contidos em alguns códices do Comentário de Simplício, (v) nos trechos das Diatribes, dos quais Arriano fez sínteses que adicionou ao Encheirídion, (vi) nas citações do Encheirídion feitas por autores antigos de séculos posteriores e (vii) nas três paráfrases cristãs. Segundo esse autor, existem exatos 59 códices contendo o Encheirídion, e nenhum deles é anterior ao século XIV. Aqueles que contêm as paráfrases cristãs são bem mais antigos, datando alguns dos séculos $X$ e XI.

Após trinta e três páginas de contextualização e esclarecimentos necessários para a leitura da obra, passa-se à tradução propriamente dita, seguida de uma extensa bibliografia acerca do estoicismo e da obra referida. Ao final da obra o livro dispõe de um Index Locorum e de um Index Rerum, seguidos de uma bibliografia complementar intitulada Textos Gregos, indicando as principais obras de autores como Plutarco e Xenofonte, por exemplo.

Esta obra de Epicteto, além de ser de suma importância para a compreensão do estoicismo imperial, também é fonte para o resgate do estoicismo antigo, uma vez que Epicteto, por lecionar o estoicismo, e não somente o praticar, descreveu diversos conceitos estoicos à luz de Crisipo de Sólis (280-208 a.C.), escolarca e principal sistematizador do estoicismo velho (300-129 a.C.).

Além de ser traduzida com muita precisão, essa obra é cuidadosamente anotada, o que a transforma em fonte de grande utilidade para os pesquisadores em estoicismo.

A obra pode ser comprada no seguinte link: https://lojas.ci.uc.pt/imprensa product_info. php?cPath=71_73\&products_id=690. Além disso, a Classica Digitalia disponibiliza a obra em pdf para download gratuito no link a seguir: https://bdigital. sib.uc.pt/jspui/handle/123456789/171.

Submetido em Julho de 2014 e aprovado em Fevereiro de 2015.
1 Disponivel em: http://seer.ufs. br/index.php/prometeus/issue/ view/107

2 Disponivel em: http://seer.ufs. br/index.php/prometeus/issue/ view/112

3 "0 punhal de Epicteto". Disponível emm: http:// criticanarede.com/encheiridion. html

4 Disponivel em: http://seer.ufs. br/index.php/prometeus/issue/ view/111

5 Dinucci, A.; Julien, A. (1912), "0 Encheirídion de Epicteto". Archai, Brasília, n.9, p. 123-136. Disponível em em: http://seer.bce. unb.br/index.php/archai/article/ view $/ 7657 / 6588$ 